Forskningsartikel

\title{
Hästen i det peri-urbana landskapet - vems tolkningsföreträde råder?
}

\author{
Madeleine Bonow
}

As horses take up an increasing amount of space in the peri-urban landscape, both the social and physical landscape undergo restructuration. This "horseification" often involves a kind of lifestyle migration, whereby new inhabitants and commuters (horse owners) of the peri-urban countryside transform the environment. Based on more than 30 interviews, this study confirms that such a restructuring of the peri-urban landscape creates conflicts between its "new" inhabitants (lifestyle migrants, horse owners) and its long-standing residents (farmers and land owners). This can be understood as a collision between groups with different ideologies and values, whereby rural practices are challenged by an urban norm. A central aspect of these kinds of "culture clashes" is that an urban norm about the landscape as an area for consumption and recreation tends to stand in direct opposition to rural values and practices where the landscape is, to a greater extent, a source of livelihood.

\section{Keywords: peri-urban landscape; horseification; conflict}

I och med att hästen tar allt större plats i det peri-urbana landskapet sker det en omstrukturering av både det sociala och det fysiska landskapet. Denna "hästifiering" omfattar ofta en typ av livsstilsmigration, där den peri-urbana landsbygdens nya invånare och inpendlare (hästägarna) omvandlar miljön. Hästarnas ökade närvaro påverkar nämligen både det privata och det offentliga rummet. Med stöd i över 30 intervjuer konstaterar studien att denna omstrukturering av det peri-urbana landskapet skapar konflikter mellan "nya" (livsstilsmigranter, hästägare) och de "gamla" som bott där sedan tidigare (jordbrukare och markägare), vilket kan tolkas som motsättningar mellan grupper med olika ideologier och värderingar där rurala förhållningssätt utmanas av en urban norm. En central aspekt av dessa "kulturkrockar" är att en urban norm om landskapet som yta för konsumtion och rekreation ofta står i motsatsställning till rurala värderingar och praktiker där landskapet i högre grad utgör en källa till försörjning.

\section{Nyckelord: peri-urban landsbygd; hästfiering; konflikt}

$\mathrm{P}$ å senare tid har vi mötts av allt fler rapporter om en flykt från staden till mer perifera områden, inte minst i kölvattnet av covid-19-pandemin. Många gånger handlar det om en kortare förflyttning från en lägenhet $i$ storstaden till en villa med trädgård i en närliggande kommun, det vill säga en så kallad peri-urban förflyttning. Den här trenden är inte helt ny, utan utflyttningen av främst barnfamiljer och urbana nedväxlare har pågått i större och mindre grad sedan 1970-talet (Forsberg \& Carlbrand 1993; Amcoff, Forsberg \& Stenbacka 1995; Amcoff 2000; Stenbacka 2001, 2011). En sak som kännetecknar samtida peri-urbana områden är den stora närvaron av hästar. Allteftersom hästintresset har ökat i Sverige har dessa djur blivit en allt större angelägenhet för både landsbygd och stad. Alltfler storstadsbor pendlar ut till den peri-urbana landsbygden där de håller sina hästar, eller bosätter sig på små gårdar i storstadens utkant där de kan vara nära dem. Hästen har kommit att bli en del av individens fritid, till skillnad från tidigare, då hästen snarare nyttjandes som en del av ett produktionslandskap för de agrara näringarna. I denna process ändras markanvändningen i de peri-urbana områdena när jordbruk läggs ner och hästarna flyttar in istället - det sker en så kallad hästifieringsprocess (Hammer, Bonow \& Petersson 2020).

Denna artikel fokuserar på den specifika form av livsstilsmigration som sker mellan urbana och peri-urbana miljöer till följd av detta ökade hästintresse. Artikelns syfte är att undersöka hur landskapet påverkas av de praktiker som hästifieringen innebär, samt vilka målkonflikter som uppstår i hästifieringsprocessen och hur 
dessa hanteras. Artikeln diskuterar också om, och i så fall hur, dessa konflikter kan förstås i relation till en urban norm. Empiriskt bygger artikeln på en intervjustudie med boende i det peri-urbana området kring Uppsala och Stockholm, som är särskilt hästtätt med sina enligt Jordbruksverket (2016) över 52000 hästar.

\section{Bakgrund och tidigare forskning: Hästifieringen av den peri-urbana landsbygden}

Termen "peri-urban" syftar på områden som ligger i övergångszonen mellan stad och landsbygd. I Sverige har de peri-urbana områdena av Glesbygdsverket definierats i relation till restiden med bil till närmaste bosättning med mer än 3000 invånare. Om restiden är 5-45 minuter definieras det som ett peri-urbant område (Glesbygdsverket 2008). Peri-urbaniseringen har lett till en expansion av staden, inte bara i fysiska termer (som bostadsbyggande med låg densitet), utan också av funktionella relationer som skapat rurala områden med urbana influenser runt städerna (Ravetz 2013: 16). De peri-urbana områdena är områden med "blandade" eller "integrerade" funktioner, där konsumtion och produktion konkurrerar om mark. Bönder, nybyggare, industriföretagare och urbana medelklasspendlare kan alla samexistera inom samma territorium, men med olika och ofta konkurrerande intressen, praxis och uppfattningar (Allen 2003). Till det yttre har de periurbana områdena landsbygdskaraktär, framförallt eftersom de gröna näringarna står för en viktig del av dess totala ekonomiska aktivitet. Men till skillnad från landsbygden har de en befolkning med heterogen sammansättning, som dessutom är i ständig rörelse. Sammansättningen och intressena hos dessa grupper tenderar dessutom att förändras över tid (Allen 2003). Saltzman (2009) har konstaterat att det peri-urbana landskapet ofta uppfattas som stadens - snarare än landsbygdens - utkant, vilket sätter staden i centrum för tolkningar av vilka normer som ska råda i området (Saltzman 2009: 9-10).

Boze (2012) menar också att den urbana inflyttade befolkningen påverkar befolkningen i den peri-urbana zonen mer än tvärtom (Boze 2012: 23). Cloke (1999) konstaterar också att inflyttare ofta tar med sig urbana attribut och förväntningar till det rurala landskap de valt att bosätta sig. De behåller de urbana attributen trots att de flyttat, samtidigt som de tar del av de olika fördelar och värden som finns på den nya platsen (Cloke 1999: 258). Samma slutsats kommer Ghose (2004) och Gosnell och Abrams (2009) fram till, nämligen att inflyttningen till den peri-urbana landsbygden också medför en förflyttning av urbana ideal och förväntningar till dessa platser, som därmed förändras både fysiskt och socialt (Ghose 2004; Gosnell \& Abrams 2009: 306). Just detta att de som flyttat dit från urbana områden tar med sig ett tolkningsföreträde är vad vi i detta temanummer kallar en urban norm, vilken får effekter för de som är bosatta på landsbygden sedan tidigare.

Under den senaste 50-årsperioden har Sverige dessutom blivit ett av de länder i Europa som har flest hästar per invånare - och det har aldrig tidigare i modern tid funnits så många hästar i landet. Majoriteten av Sveriges 355000 hästar finns i och kring de stora städerna (Jordbruksverket 2016). Närmare en tredjedel av Sveriges invånare har på något sätt kontakt med hästar och hästrelaterade verksamheter, och så många som en halv miljon svenskar rider regelbundet. Parallellt med att hästarna tar större plats på den peri-urbana landsbygden ändras även de ekonomiska förutsättningarna där, exempelvis genom att huspriserna stiger, speciellt på små gårdar. Det är inte otänkbart att detta i förlängningen kan leda till att de som bor där sedan tidigare, $\mathrm{i}$ likhet med den utveckling som skett på vissa kustorter, inte längre kommer ha möjlighet att bo kvar. Samtidigt har hästarna till viss del blivit den peri-urbana landsbygdens räddning $\mathrm{i}$ och med att de bidrar till de befintliga jordbrukets inkomster på flera olika sätt, bland annat genom att lantbrukare producerar och säljer hästfoder eller hyr ut stallplatser. Idag är hästnäringen den femte största inkomstkällan för jordbruket, och omsätter även stora summor varje år för andra grupper (Held, Macuchova, Alnyme \& Andersson 2018).

Samröret med hästar sker alltså idag främst på den peri-urbana landsbygden, vilket innebär en förflyttning av de människor som vill vara nära hästarna. Sådan förflyttning sker antingen genom en daglig pendling ut från staden eller förorten till hästen eller i form av en permanent utflyttning. I denna bemärkelse kan hästifieringen på den peri-urbana landsbygden förstås som en form av livsstilsmigration (amenity migration) (Cadieux \& Hurley 2011), där man flyttar till en plats där de kulturella eller naturliga ekotjänsterna är bättre än på den förra bostadsorten (Gosnell \& Abrams 2009). Sociologer, planerare, kulturgeografer och andra har studerat de sociala och ekonomiska konsekvenserna av livsstilsmigration sedan trenden uppstod på 1970-talet (se t.ex. Cherry \& Rickman 2010; Winkler, Deller \& Marcouiller 2015).

\section{Kulturkrockar mellan "nya" och "gamla" invånare}

En hel del forskning har fokuserat på "kulturkrocken" mellan nya och "gamla" boende när det gäller deras attityder till samhällsfrågor (Ghose 2004; Gosnell \& Abrams 2011; Krannich, Luloff \& Field 2011; Boucquey, Campbell, Cumming, Meletis, Norwood \& Stoll 2012). En nyckelfråga har varit hur livsstilsmigranterna formar platsen till vilken de flyttar. En hel del av denna forskning undersöker konflikter mellan nya och "gamla" invånare, ofta över verkliga eller upplevda skillnader i värderingar och attityder som vanligtvis kallas "kulturkrockar" (Marcouiller, Delle \& Green 2005; Gosnell \& Abrams 2011; Armstrong \& Stedman 2013). Enligt Smith och 
Krannich (2000: 399) utgår begreppet kulturkrock i det här sammanhanget från antagandet att nykomlingar av urbant ursprung för med sig en viss sociokulturell identitet till de samhällen till vilka de migrerar och att denna identitet och den tillhörande värdeinriktningen skiljer sig från dem som innehas av de som bott på platsen länge. Man har sett att det finns vissa skillnader mellan "nya och "gamla" som kan spela en roll i värdeorienteringen (Smith \& Krannich 2000; Elgåker 2011; Qin 2015). Till exempel tenderar nyinflyttade invånare att ha högre utbildning och inkomster än de som bott på platsen länge (Elgåker 2011; Krannich, Luloff \& Field 2011). En hel del av den forskning som skett kring kulturkrockar fokuserar på invånarnas attityder kring specifika miljörelaterade frågor såsom tillgång till privat egendom eller förvaltning av mark och markanvändning (Robbins, Meehan, Gossnell \& Gilbertz 2009; Matarrita-Cascante, Stedman \& Luloff 2010; Gosnell \& Abrams 2011; Armstrong \& Stedman 2013; Ulrich-Schad, \& Qin 2018). Även om det är vanskligt att prata om urskiljbara kulturer, indikerar dessa uppgifter att det finns konfliktlinjer som handlar om attityder och klass.

Det har dock visat sig att boendetiden inte alltid är avgörande vad gäller attityder till samhällsfrågor, inklusive sådana som är kopplade till miljö. Detta har förklarats med att de så kallade livsstilsmigranterna inte är en homogen grupp (Boucquey m.fl. 2012). Det har också konstaterats att den speciella typ av livsstilsmigration som behandlas i min studie - det vill säga förflyttning för att kunna hålla på med hästar - leder till förändringar i den rumsliga fördelningen av aktiviteter (Latimer \& Birke 2009; Birke \& Brandt 2009). När en hästgård etableras påverkas både det privata och det offentliga rummet, inte minst eftersom landskapsrummet förvandlas genom att man när man bygger stall och anlägger hagar, ridbanor och ridhus omformar själva platsen. Sådana anläggningar kräver kapital, vilket innebär att det blir de resursstarka som har möjlighet att omforma platsen på detta sätt. Ekonomiska resurser är därför en förutsättning för dessa förflyttningar snarare än en drivkraft bakom den, eftersom en bättre ekonomi på så sätt möjliggör livsstilsmigrationen. Markpriserna går också upp i områden som anses attraktiva och detta skapar en utträngning av de som tidigare bott på platsen (Sutherland 2021).

Därtill påverkas de peri-urbana områdena av att hästarna rör sig i det offentliga rummet, till exempel när ägarna rider ut eller förflyttar sina hästar fysiskt mellan träningar och tävlingar på andra anläggningar. Praktikerna som påverkar landskapet begränsar sig alltså inte till själva stallet och markerna i nära anslutning till dem, utan utövas i hela närområdet och på vägar till och från det peri-urbana området. Man har sett att livsstilsmigranter omstrukturerar landskapet på flera sätt och att de i regel har en annan syn på ägande och markanvändning. "Nya" och "gamla" invånare har till exempel olika uppfattning om hur man kan stängsla in sin mark och de förstnämnda är ofta mindre villiga att tillåta andra att beträda deras mark (Yung \& Belsky 2007; Boucquey m.fl. 2012). Livsstilsmigration kan enligt Laitos och Ruckriegle (2013) leda till en massiv invasion av urbana beteendemönster till landsbygdsområdena (Laitos \& Ruckriegle 2013). Invasionen riskerar att förstöra de befintliga strukturerna i landskapet på olika sätt, strukturer som kan ha byggts upp under många generationer och möjliggjorts genom väl underbyggda sociala nätverk, där till exempel bruket av allmänna resurser reglerats.

Det faktum att nyttjande och kontroll över marken utgör grunden för hästhållning och hästifiering och flera grupper därmed konkurrerar om platsanvändning på den peri-urbana landsbygden kan ge upphov till en serie konflikter om resurser, utrymme och identitet (Elgåker 2011). Tillberg Mattson (2004) och Långstedt (2008) har konstaterat att motsättningar kan uppstå mellan den ursprungliga landsbygdsbefolkningen som ofta äger en stor del av marken och de nya invånarna, i det här fallet de inpendlade ryttarna och livsstilsmigranterna. De sistnämnda reproducerar till viss del det urbana tolkningsföreträdet när de flyttar in eller reser till sina hästar (Tillberg Mattson 2004; Långstedt 2008), vilket jag menar påverkar hur dessa konflikter kan ta sig i uttryck.

Konflikter uppstår inte enbart beroende på vilken typ av aktiviteter man deltar i utan även av att användarna har olika mål som kolliderar med varandra. Det här kan gälla både konflikter inom och mellan olika användargrupper. Inom gruppen ryttare kan sådana konflikter till exempel handla om att man är oense över varandras beteende eller användning av samma område. Konflikter mellan grupper kan bland annat röra konflikter mellan ryttare och hundägare, eller mellan ryttare och de som nyttjar, eller inte minst de som äger, områden för jord- och skogsbruk (Ankre 2019). Vad gäller det sistnämnda menar Ankre att konflikter pekar på en problematik gällande tolkningen av nyttjandet av allemansrätten och privat ägande. Hur man sedan reagerar på en konflikt kan variera. Antingen agerar man för att minska eller undvika konflikten och ändrar sitt beteende eller så ändrar man sin aktivitet för att anpassa sig till situationen. Ibland kan en användare istället uppleva besvikelse och minskad tillfredsställelse när konflikter uppstår, vilket kan innebära att man i framtiden för att uppnå sina mål väljer ett annat område för sin aktivitet. Om bara en grupp upplever målkonflikter är de asymmetriska, till exempel att de som vandrar stör sig på de som rider, eller att markägare stör sig på ryttare men inte vice versa (Ankre 2019: 40-41).

\section{Metod och material}

Empiriskt bygger artikeln på sammanlagt 31 stycken intervjuer som utförts i samband med olika 
forskningsprojekt i tre olika perioder. ${ }^{1} 20$ strukturerade intervjuer genomfördes på 20 olika gårdar i Stockholmskommunerna Upplands-Bro, Ekerö och Huddinge under åren 2014 och 2015. Intervjupersonerna bestod av hästägare som hade sina hästar uppstallade i inackorderingsstall på dessa gårdar men bodde på annan ort (9), personer som ägde och drev gårdar med inackorderade hästar ${ }^{2}$ (7) samt personer som var ansvariga för ridskoleverksamhet (4). Medan samtliga av de intervjuade ryttarna var kvinnor, var fyra av sju gårdsägare män.

Därefter har materialet kompletterats i två olika omgångar. 2015-2016 genomfördes sex (6) djupintervjuer med kvinnliga hästföretagare verksamma i Stockholm och Uppsala län ${ }^{3}$, och 2021 genomfördes ytterligare fem (5) intervjuer med gårdsägare och markägare som var bosatta i Stockholm eller Uppsala län och alla bedrev någon slags jord- eller skogsbruksproduktion på sina marker samt hade hästar på sina gårdar. (Fyra av dessa var kvinnor.) I intervjuerna med hästföretagarna framkom bland annat svårigheter och konflikter som kan hindra företagsverksamheten och de kompletterande intervjuerna från 2021 syftade specifikt till att få en fördjupad förståelse för de målkonflikter som hade utkristalliserats i de tidiga intervjuerna. Intervjuernas längd varierade något mellan projekten, men varade mellan 30 minuter och två timmar. Samtliga citat i artikeln är hämtade från dessa undersökningar, men för att bevara intervjupersonernas integritet anges inte källa till varje citat.

I analysen till den här artikeln har både det äldre och det nya materialet analyserats och tematiserats med särskilt fokus på de upplevda målkonflikter som utkristalliserades $\mathrm{i}$ intervjuerna. Det övergripande temat är de konflikter som uppstår mellan livsstilsmigranterna - de inpendlande ryttarna som reser till sina hästar och sedan åker "hem" igen - och andra aktörer på den peri-urbana landsbygden, både de inflyttade livsstilsmigranterna och de som bott längre på platsen. Här görs en analytisk skillnad mellan de inpendlande ryttarna som utgör ett slags "landskapskonsumenter" samt mellan "nya" och "gamla" invånare. Analysen i texten berör olika målkonflikter som uppstår på grund av landskapets omstrukturering i hästifieringens spår, asymmetriska målkonflikter eller makten över marken och sist slutligen målkonflikter som uppstår kring uppfattningar om "vi och dom".

\footnotetext{
${ }^{1}$ Dessa intervjuer genomförde inom ramen för projektet The role of horses in peri-urban landscapes - contributing to healthy life styles and ecosystems or environmental hazards or both? Syftet med detta projekt var att få en allmän bild av hästen i det peri-urbana landskapet, där en av delfrågorna rörde konflikter som kan uppstå kring hästen i storstadens närhet. Resultatet har publicerats i Hammer, Bonow \& Petterson 2017, 2020.

${ }^{2}$ Alla dessa sju bedrev någon slags jord- eller skogsbruksproduktion på sina marker, som till exempel foderproduktion.

${ }^{3}$ Dessa intervjuer ägde rum mellan 2015 och 2016 i en studie som rörde som rörde genus och entreprenörskap inom hästnäringen. Resultatet har publicerats i Bonow, Hammer \& Petterson 2017.
}

\section{Målkonflikter kring landskapets omstrukturering vid etablering av hästgårdar.}

I materialet framkom att när ett område genomgår en hästifieringsprocess så förändras miljön ganska radikalt. Hästhagar stängslas, ridbanor och ridhus anläggs och stall byggs. Gårdarna är ofta små vilket gör dem möjliga att hägna in och nya gårdsägare sätter ofta upp grindar och staket kring sina ägor. Detta uppfattades av de "gamla" invånarna som intervjuades som försök stänga andra ute från att kunna passera. Som en av intervjupersonerna uttryckte det: "När NN flyttade in så stängde hen av hela vägen och vi tvingas nu gå runt och ut på landsvägen för att ta oss till skogen."

De som levt på platsen längre tolkade ett sådant förfarande som ett tecken på en förskjutning i synen på egendom, på vad som är "mitt och ditt". Förfarandet att stängsla in och därmed stänga andra ute från sina ägor kan förstås som ett urbant beteendemönster, som förts in i den mer rurala miljön av de nyinflyttade (Laitos \& Ruckriegle 2013). Rent konkret medförde detta inte minst irritation bland grannar som var vana att kunna rida eller stöva fritt genom gårdarna och vissa upplevde att detta beteende var särskilt vanligt bland "Stockholmarna". Liknande skillnader i syn på egendom och markägande har också konstaterats i tidigare forskning, där livsstilsmigranter har visat sig skilja sig åt i sin syn på hur man skall se på ägande och markanvändning och att nykomlingar är mindre villiga att tillåta andra att beträda marken kring gården (Yung \& Belsky 2007; Boucquey m.fl. 2012). I mina intervjuer menade "nykomlingarna" dock att instängslingarna inte berodde på en urban norm utan snarare handlade om omsorg om hästarna eller andra djur, som skulle skyddas från att komma ut på vägen eller bli överkörda av bilar. En annan anledning var att man vill skydda sig mot inbrott, vilket man menade att hästgårdar blivit allt mer utsatta för.

Ett uttryck för denna målkonflikt kring landskapets omstrukturering fick en av intervjupersonerna erfara när hon var ny på gården och hade flyttat sitt staket lite för att hagen också skulle innefatta lite skog. Hon beskrev hur hon hade blivit utskälld av andra ryttare $\mathrm{i}$ området - också inflyttade livsstilsmigranter - för att hon skar av bästa ridvägen. De hade krävt att en ny ridstig skulle beredas och broar över diken skulle anläggas. En ny ridväg anlades förvisso, men inte några broar, och händelsen gav upphov till en kvarvarande konflikt.

Flera av intervjupersonerna beskrev hur de kände sig väldigt motarbetade av de som bott på platsen länge, till exempel när de ville uppföra nya stall eller ridhus på sina ägor. Grannarna som bott länge på platsen hade $i$ flera fall överklagat bygglov med motiveringar som att sådana anläggningar skulle utsätta dem för "allergener och odörer", eller att det skulle förstöra deras sjöutsikt och potentiellt sänka marknadsvärdet på huset. En granne hade framfört argumenten att intervjupersonen inte fick bygga nytt stall eftersom marken till gården 
ansågs för liten för att rymma fler hästar och ett nytt stall skulle bara förvärra saken. Enligt Eklund, Andersson, Brandt, Sjöblom och Riska (2006) är det just sådana saker som kan skapa konflikter mellan hästägare och grannar.

\section{Asymmetriska målkonflikter eller makten över marken}

Intervjuerna visade att en konfliktorsak handlar just om att de nya hästgårdarna har begränsade markytor, vilket leder till att hästarna kommer nära inpå grannarna, de kringliggande gårdarna och bostadsområdena. Det saknas mark att rida på, vilket leder till att möjligheter att rida ute i skog och mark förutsätter att ridningen sker på någon annans mark. Storleken på ägorna var en viktig faktor i detta sammanhang. Till skillnad från smågårdsägarna hade de stora markägarna större möjligheter att anlägga ridvägar på sina egna marker, varför de och deras inackorderade hästägare slapp rida på någon annans mark. Här kan vi tala om en asymmetrisk målkonflikt mellan de som hade hästar på små gårdar och såg det som självklart och oproblematiskt att få rida i skog och mark, medan markägarna var av en helt annan åsikt.

Den här typen av konflikter kan delvis förstås som kopplade till olika tolkningar av allemansrätten, framförallt i relation till ridning. ${ }^{4}$ Även om det enligt allemansrätten är tillåtet att rida på annans mark, får vistelsen inte får leda till att markägaren lider skada eller olägenhet eller att dennes ekonomiska intressen kränks (Bengtsson 2004: 12). I intervjuerna uttryckte de små gårdsägarna, med hänvisning just allemansrätten, förväntningar på att landskapet skulle vara öppet för ridning. Här framträdde tolkningen av allemansrätten som en vattendelare mellan inpendlade ryttare och "gamla" markägare. I den här målkonflikten var förhållandet ofta asymmetriskt.

Bland de ryttare som intervjuades under åren 2014-2016 var de flesta "inpendlare" som reste från sin bostadsort till sina hästar som stod inhyrda i stall i den peri-urbana zonen. En vanlig anledning till att de som stadsbor hade sin häst uppstallad i den peri-urbana zonen var att de ville rida ute i landskapet. Här uppstod då en målkonflikt mellan markägare och ryttare om rätten att nyttja marken. Det här gav upphov till en asymmetrisk målkonflikt, där de intervjuade markägarna uppgav att de, när de hade konfronterat ryttare på deras marker, oftast mötts av oförstående och kommentarer i stil med att: "Allemansrätten gäller, jag rider vart jag vill”. En möjlig tolkning till varför denna konflikt uppstår är, menar jag, att de urbant boende

\footnotetext{
${ }^{4}$ Alla i Sverige får vistas ute $\mathrm{i}$ naturen på annans mark regleras vistelsen i allemansrätten. Allemansrätten ger var och en rätt att utan markägarens medgivande vistas i naturen och att där plocka vilda bär blommor och svamp. Det är tillåtet att färdas till fots, rida, cykla och åka skidor. Den som bryter mot detta har alltså passerat gränsen för vad som är tillåtet enligt allemansrätten (Bengtsson 2004: 12).
}

inpendlarna var vana att få vistas var de ville, precis som de gör i en stad och i dess parker. De reflekterade inte över att marken i de peri-urbana områdena ägs av någon och utgör underlag för ägarens försörjning.

De ryttare som bott på en plats länge uttryckte i intervjuerna en större medvetenhet om var man kunde rida och när, och varför det förhöll sig så. De hade ofta kommit överens med markägarna när, var och hur man fick rida och försökte i regel hålla sig till dessa överenskommelser för att inte förstöra grannsämjan. Sådana överenskommelser bestod i flera fall av att de intervjuade markägarna hade markerat upp ridslingor i sin skog där de försökt ge lite instruktioner om var det var lämpligt att rida och vad man skall tänka på när man rider $\mathrm{i}$ skogen (se bild 1). De försökte på så sätt minimera skadorna och slitaget som kunde uppstå.

Markägarna upplevde ändå att det blev konflikt med ryttarna. De "nya" ansåg att markägarna skulle kunna "bjussa" på sin "mark". "Du har ju så mycket och jag så lite", var ett argument som framförts av de små "nya" markägarna för att rättfärdiga att de red där de inte var lämpligt. Markägarna vittnade om att det var på så sätt som skogen reds sönder: "Det är ingen som frågat mig om lov trots att jag satt upp skyltar med mitt telefonnummer [...] Man bör alltid fråga om lov", uttryckte sig en av markägarna. En annan hade fått sin mark uppsnitslad av andra stallägare som lovat sina inackorderade ryttare att rida där, vilket väckte stor irritation. Markägarna påpekade att det var de nya, både de nyinflyttade och inpendlarna som gjorde på detta vis. Alla markägare i undersökningen hade själva hästar på sina gårdar och de var väl medvetna om när det var lämpligt att rida på olika platser och när det tvärtom riskerade att förstöra marken. En av intervjupersonerna uttryckte till exempel problem med ryttare som rider när marken är alltför blöt: "Jag har själva hästar och väljer att inte rida i skogen när det kommit mycket regn och då blir man väldig ledsen när andra rider sönder min skog".

En annan tydlig målkonflikt uppstod när markägarna försökte begränsa den "fria rörligheten", det vill säga genom att stänga av delar av skogen eller en väg eller genom att sätta upp skyltar om att ridning var förbjudet på en viss plats (se bild 2). Här ansåg markägarna att de hade rätt att göra så för att skydda sin mark från slitage, medan ryttarna ansåg att det begränsade deras nyttjande av allemansrätten och en intervjuperson beskrev detta förfarande som "olagligt och jäkligt irriterande".

Markägarna i undersökningen förklarade att de stängde av sin skog för ridning eftersom den annars riskerade att bli för upptrampad. Upptrampad mark, menade de, kan leda till ekonomiska förluster då trädens rötter skadas vid för intensiv ridning, vilket $\mathrm{i}$ sin tur kan leda till trädröta och låga virkespriser. Markägarna var alla överens om att allemansrätten därmed missbrukades genom ridningen, eller som en av dem uttryckte det: 


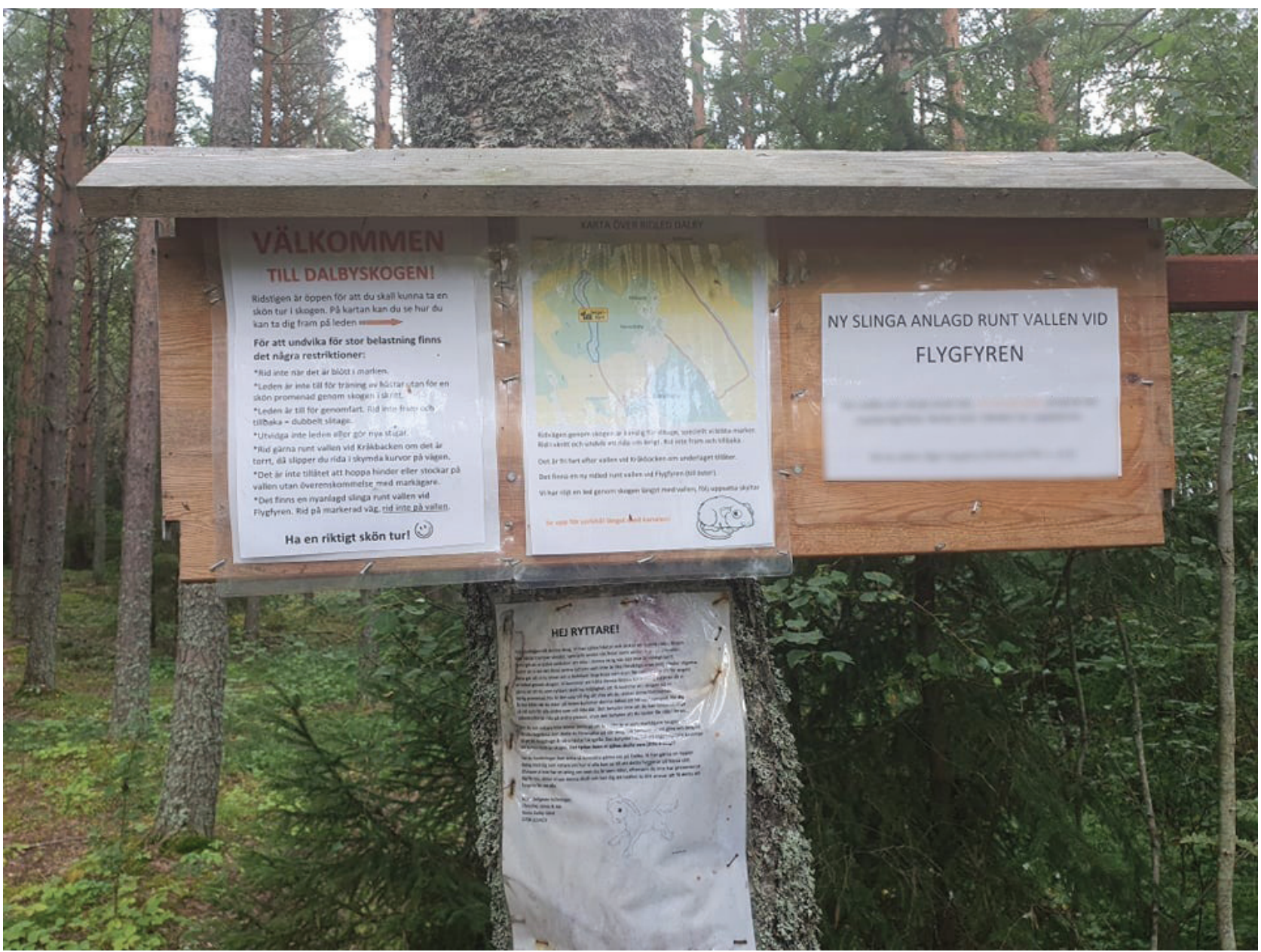

Bild 1. Exempel på ridslinga i skogen. Foto: Madeleine Bonow.

Att säga att man får rida på annans mark är alldeles för enkelt. Den [allemansrätten] ger dig ingen rätt att skada annans mark, men när är det skador? Att rida sönder rötter och göra nya stigar är skador. [...] en gång är kanske ingen gång men en stig är skada.

Även här förelåg en tydlig målkonflikt mellan de som vill nyttja landskapet för rekreation och de som vill använda det som produktionslandskap. Ryttarna menade att om de bara fick rida på en enda stig i skogen skulle den snabbt bli bredare och lerigare än om de fick rida lite mer fritt på flera stigar, vilket skulle leda till färre trampskador på trädens rötter.

En annan asymmetrisk konflikt som uppdagades i studien kan kopplas till att majoriteten av nya gårdsägare och ryttare främst bestod av kvinnor, medan nästan alla de stora markägarna som omgärdade deras gårdar var män. Flera av dem upplevde att konflikten berodde på ett ojämlikt maktförhållande som bottnade i det faktum att de var kvinnor med lite mark. Det upplevdes inte bara som en konflikt mellan nya och gamla utan snarare som en konflikt som handlade om genus och makt. I den här konflikten upplevde de små gårdsägarna (de kvinnliga livsstilsmigranterna) att de "stora" markägarna kunde göra som de ville. En av intervjupersonerna uttryckte det som att:

Vi små kvinnliga gårdsägare har ingen chans mot de stora gårdsägarna, alla dessa män som sitter på all makt och kan besluta om jag skall få rida på deras mark eller köpa foder eller få min gödselcontainer tömd.

Någon uttryckte det som att "han hade nog stängslat hela skogen om han kunde, men som tur är han för snål för det". En annan hade upplevt just att vägarna hade stängslats av med höga staket så att det blev omöjligt att rida igenom.

[...] de har råd att stängsla in hela klabbet, vilket är helt regelvidrigt och bryter mot allemansrätten, men är man stor markägare kan man bete sig som man vill. Allt handlar om makt och muskler och vi små markägare kan inte hävda oss i detta krig.

Sammanfattningsvis visar intervjumaterialet att en tydlig asymmetrisk målkonflikt uppstod mellan de som hade hästar på små gårdar i den peri-urbana områdena och som såg det som självklart och oproblematiskt att 


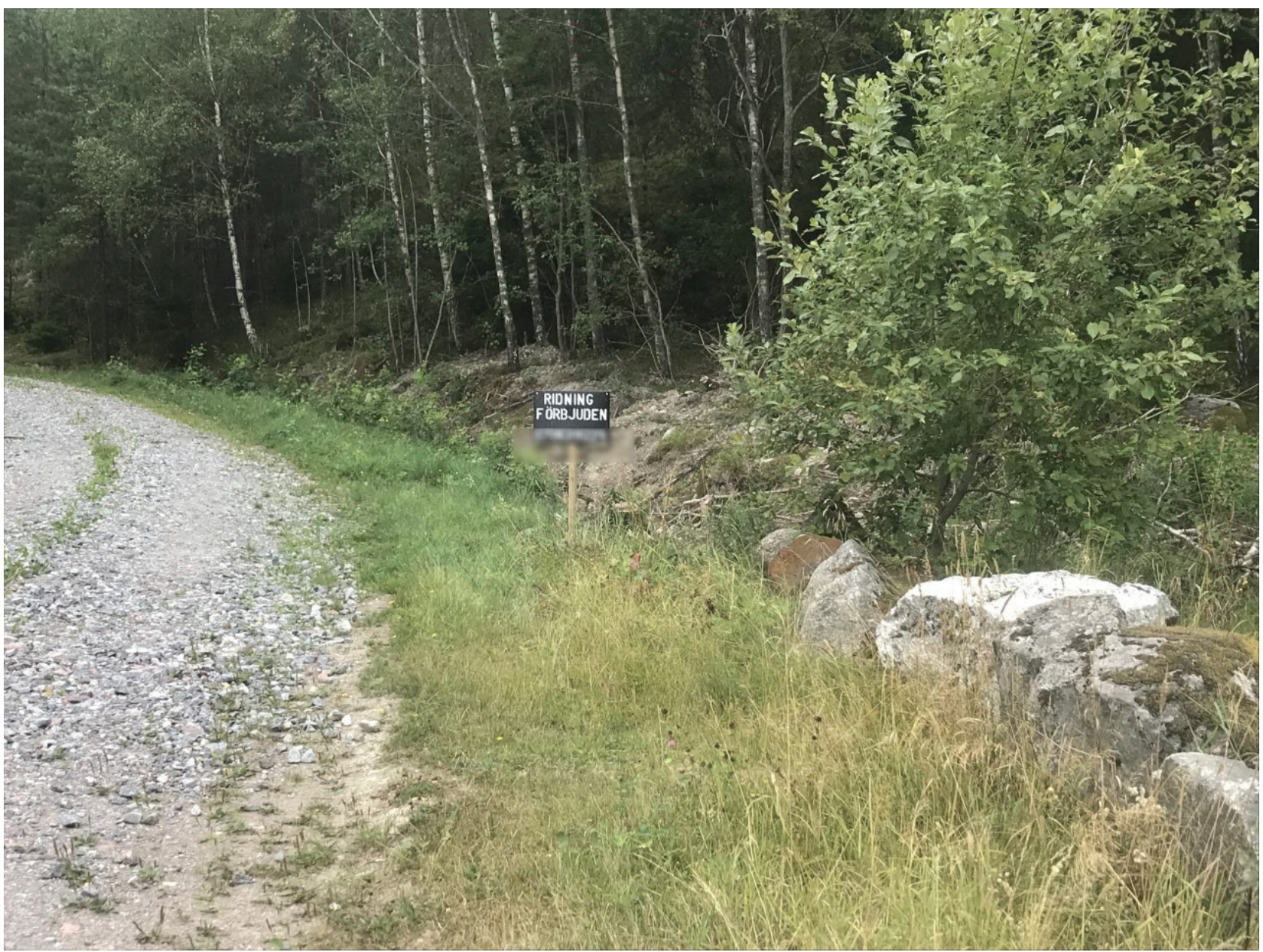

Bild 2. "Ridning förbjuden!" Foto: Madeleine Bonow.

få rida i skog och mark, och markägarna som var av en helt annan åsikt. Konflikterna ledde till irritation och i vissa fall långvarig osämja mellan de olika grupperna.

\section{"Vi och dom": Grupperingar i den peri- urbana miljön}

Något som visade sig under intervjuerna var en uppdelning mellan olika grupper i "vi och dom". En tydlig uppdelning återfanns i två grupper av "nya" användare av de peri-urbana landskapet: de inflyttade livsstilsmigranterna samt de som bara vistas tillfälligt där, det vill säga den urbana pendlade ryttargruppen. Den tredje gruppen utgjordes av de som bott på platsen längre, de "gamla". Benämningar som "stockholmare", "08:or", eller "stockholmstanter", "islandshästfolket" och "skogsmullarna" användes frekvent för beteckna alla som tillhörde de "nya" grupperna. De "nya" benämnde istället de som bott på platsen längre som "sura tanter eller gubbar" eller "maktfullkomliga markägare".

Under intervjuerna med markägarna framträdde en tydlig bild där nästan samtliga menade att det var nyinflyttade hästägare som inte bott på landet förut eller "tanterna" från Stockholm som förväntade sig att få rida var och hur det ville; att det var de som inte kunde uppföra sig och respektera andras mark. Ett exempel på detta var den vanligt återkommande beskyllningen att markskadorna berodde på ägare till islandshästar. En av markägarna uttryckte det som att "det är islandshästfolket, skogsmullarna som kommer och rider sönder vår mark". Flera intervjupersoner påpekade att när en anläggning med islandshästar startar eller utökar sin verksamhet så ökar slitaget på skog och mark automatiskt. Om en stor mängd hästar rider ut från gården varje dag året om så kommer landskapet ofrånkomligen att förändras genom att nya stigar skapas.

Bland de inpendlade ryttarna var uppfattningen en helt annan. De upplevde inte att de gjorde något fel och bland berättelserna förekom en och samma företeelse, nämligen den sura "tanten eller gubben" som förvägrade dem att rida på stigar och vägar. Ryttarna ansåg att deras upplevelse och utevistelse stördes och hindrades av att de inte kunde rida var de och när de ville. Skyltar som deklarerade ridning som förbjuden, eller avspärrningar över stigar och vägar hindrade dem från att ta sig mellan olika skogsområden. Ryttarna upplevde att de ofta blev förhindrade från att rida på vissa ställen och utsatta för anklagelser om att förstöra marken. Det obehag detta medförde att vissa ständigt var 
rädda för att bli utskällda och påhoppade när de var ute och red, och hade fått vissa att flytta och byta stall för sina hästar. Intervjupersonerna uttryckte det som att det var jättejobbigt med den ständiga konfrontationen, att vara beredd på att bli attackerad varje gång de rider. Livsstilsmigranterna som bott längre på platsen hade löst det genom att de hade slutat rida på vissa ställen av rädsla för att bli utskällda, eller som en av dem uttryckte det: "Jag kan inte riskera att komma med små barn och bli utskälld, de blir rädda".

Något som också tycktes väcka starka känslor var det faktum att hästar lämnar efter sig relativt stora högar avföring (se bild 3). En intervjuperson beskrev hur hennes granne "blir oerhört uppretad av att man rider på hans vägar och det minsta bajs på vägen väcker ilska". Flera jag intervjuade var väldigt medvetna om problemet och försökte styra ut hästen i vägkanten eller bort från stigen när den behövde uträtta sina behov och livsstilsmigranter som bott längre tid på platsen hoppade av sina hästar och sparkade ner det i diket, för att undvika arga kommentarer som "plocka bort skiten efter dig!"

I den här frågan blev det ganska tydligt att de som bodde på platsen - oavsett om de bott där länge eller ej - hade en ganska klar åsikt: man tar bort efter sig, för det är inte så trevligt att ha stora högar på vägen när man skall passera gåendes eller med bil. Syndabockarna blev inpendlarna som inte ansågs kunna sköta sig.

\section{Avslutande diskussion}

I denna studie har det utkristalliserats två grupper av "nya" användare av de peri-urbana områdena som båda har ett urbant ursprung, dels den urbana ryttargruppen som pendlar till sina hästar och dels de som nyligen bosatt sig i dessa områden: livsstilsmigranterna. I likhet med tidigare studier visar min undersökning att de "nya" användarna av den peri-urbana landsbygden (inpendlande ryttare och nya gårdsägare) tenderar att ta med sig sina urbant normativa och värderingar i sitt förhållningssätt till användandet av den peri-urbana landsbygden och då uppstår lätt målkonflikter. Dessa konflikter kan vi tydligt se i och med den hästifiering som sker i och kring våra större städer. I studien visade det sig att hästarna $i$ sig inte var orsaken till målkonflikterna utan snarare hur den nya användningen av hästar påverkar den omgivande miljön. De boende - både "gamla" och "nya" på den peri-urbana landsbygden som annars inte har något emot hästar, upplevde särskilt problem med att hästarna trampade sönder deras mark

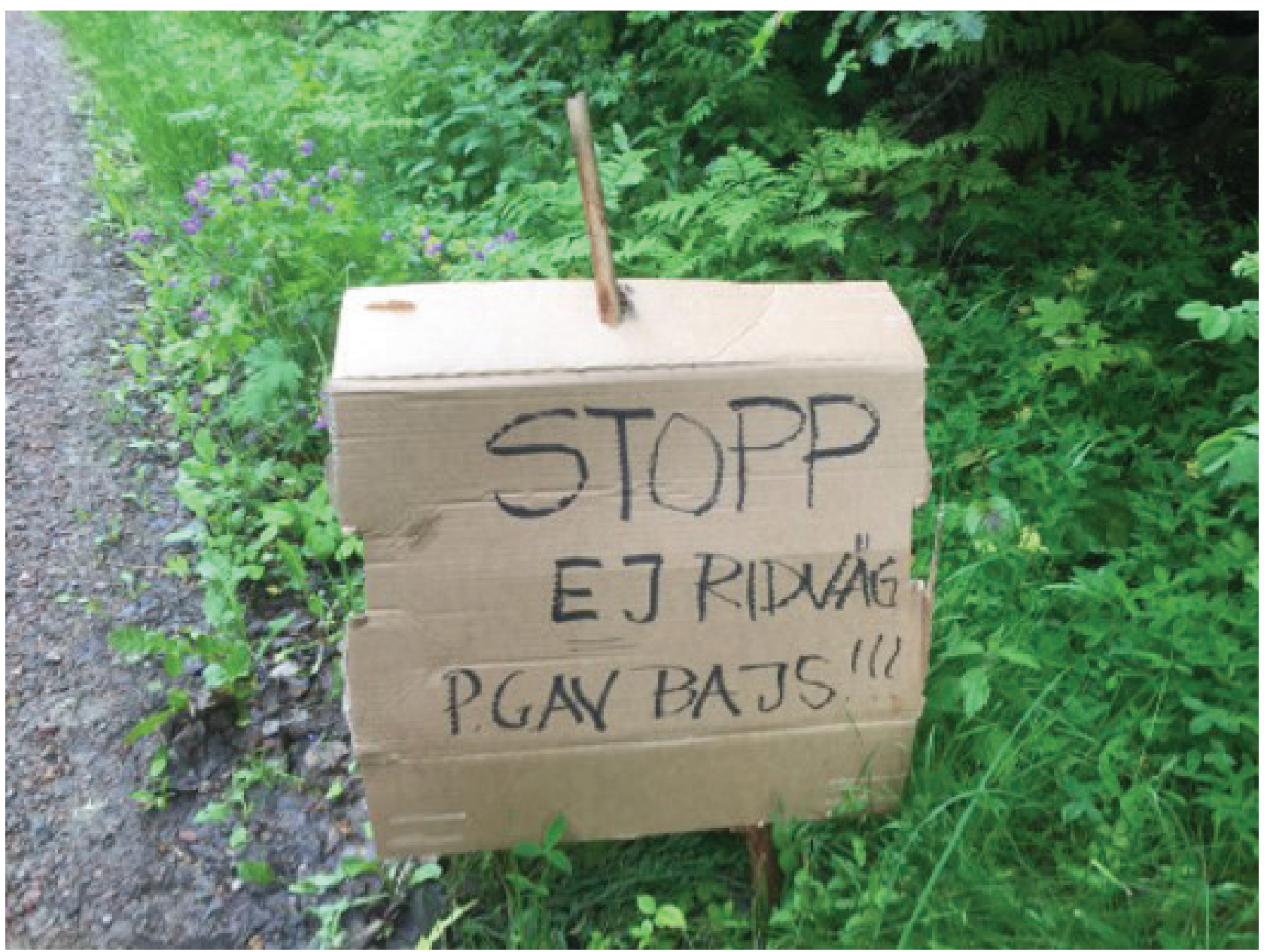

Bild 3. Hästarnas avföring ger ofta upphov till konflikter. Foto: Madeleine Bonow. 
eller då de tyckte att djuren kom för nära inpå deras bostäder (se även Eklund 2006; Långstedt 2008).

När det gäller konflikterna kring allemansrätten blev det tydligt att det fanns en diskrepans mellan parternas uppfattningar om sitt eget och andras agerande. Förhållningssättet till allemansrätten skiljde sig ganska markant mellan de som tillhör den urbana inpendlade ryttargruppen och "gamla" boende. Här skapades konflikterna både av de inpendlare gruppen som inte förstår hur man bör agera när man rider på någon annans mark, och av markägare som hindrar ryttarna att utnyttja allemansrätten. Det går på så sätt att koppla ihop de asymmetriska målkonflikterna med den urbana normen, vilket innebär att de "nya" inte ser sitt eget tolkningsföreträde, utan ser sig som "oförskyllt" påhoppade när de konsumerar den peri-urbana landsbygden via hästryggen.

Mot bakgrund av studiens resultat konstaterar jag att hästifieringen av den peri-urbana landsbygden måste förstås utifrån ett socialt- såväl som från ett markanvändningsperspektiv. I denna studie orsakas många av målkonflikterna av skilda åsikter om hur det peri-urbana landskapet skall användas. Ibland skapas det av livsstilsmigranten som anser att deras tolkningsföreträde skall gälla. En möjlig tolkning är att dessa människor har köpt en idé, livsstil och en plats och därmed anser sig ha rätt att nyttja landskapet som de anser passa dem. En sådan inställning kan leda till målkonflikter som beror på att dessa personer tar med sig en urban norm till de peri-urbana områdena, vilka inte är förenliga med de som annars finns på platsen. Min studie visar att denna norm ofta rent konkret hänger samman en okunskap om hur man bör nyttja landskapet, till exempel för att undvika att tillfoga skada på markerna. Studien visar dock också att konflikter kan uppstå på grund av dikotoma grupperingar mellan den peri-urbana landsbygdens "vi och dom", där de nya livsstilsmigranterna ibland ges skulden av andra skäl, för beteenden som på olika sätt inte anses passa på platsen. Detta kan till exempel handla om att de anses rida på fel platser, ha leriga hagar, flytta sina hagar där andra vill rida eller lämna hästspillning på vägen.

Studien visar tydligt på behov av olika typer av konfliktlösning. En lösning som också efterfrågades av flera av "de nya" livsstilsmigranterna var ökad dialog mellan de "nya" och "gamla" på en plats. Med tanke på att alltfler nu flyttar till dessa områden, är detta förmodligen en förutsättning för att samexistensen på den peri-urbana landsbygden skall fungera. En annan, men på grund av markpriserna mer svårrealiserad, lösning på dessa konflikter handlar om vikten av tillräckligt mycket mark vid nyetablering av hästgårdar, vilket skulle minska trycket på andras mark vid ridning. Ytterligare en lösning skulle kunna vara anläggningar av ridvägar med preparerad mark. Sådana finns redan i en del kommuner kring Stockholm och Uppsala, där kommunerna varit med och finansierat anläggandet av dem. För att detta ska fungera krävs dock att markägarna är villiga att upplåta mark för det, vilket min studie visar inte alltid är fallet. Avgörande för att denna lösning skall fungera är att ridvägarna måste vara långa och sammanbundna på ett bra, säkert och smidigt sätt så att alla ryttare i ett område får tillgång till dem. Avslutningsvis konstaterar jag att hästifieringen av den peri-urbana landsbygden och den, ganska radikala, omvälvning som nu sker ofta leder till konflikter mellan olika grupperingar. Dessa konflikter uppstår när en urban norm där landskapet ses som yta för konsumtion och rekreation får tolkningsföreträde framför en rural inställning där landskapet är en källa till försörjning. Som min intervjustudie visar är dessa konflikter ofta komplexa och handlar om en mängd aspekter som rör alltifrån syn på egendom, uppförandekoder och kulturellt bestämda förväntningar och kan ge upphov till starkt negativa känslor och upplevelser för alla inblandade. Med tanke på att hästifieringen av dessa miljöer inte visar några tecken på att avta menar jag att det finns behov av att hitta lösningar där "nya" och "gamla" invånare kan samexistera på ett bättre sätt.

\section{Författarpresentation}

Madeleine Bonow är docent i geografi och verksam vid Södertörns högskola. Hennes forskningsområden berör landskapsförändringar både inom staden där stadsodling varit i fokus och det peri-urbana landskapets strukturomvandling från jordbrukslandskap till hästlandskap. Hon har också studerat hur man kan främja regional utveckling genom framförallt småskalig matproduktion.

\section{Referenser}

Amcoff, Jan (2000). Samtida bosättning på svensk landsbygd. Uppsala: Uppsala universitet.

Amcoff, Jan \& Forsberg, Gunnel \& Stenbacka, Susanne (1995). Inflyttning och nybyggnation i Mälardalens landsbygd, Delrapport inom projektet Mälardalens landsbygd i förändring. Arbetsrapport nr 155, Kulturgeografiska inst. Uppsala: Uppsala universitet.

Ankre, Rosemarie (2019). Friluftslivkonflikter i svenska kustlandskap ur ett planerings- och användarperspektiv: Studier av Luleå och Blekinge skärgårdar (doktorsavhandling), Karlskrona: Blekinge Tekniska Högskola.

Armstrong, Andrea \& Stedman, Richard C (2013). Culture Clash and Second Home Ownership in the U.S. Northern Forest. Rural Sociology 78(3), 318-45.

Bengtsson, Bengt (2004). Allemansrätten - Vad säger lagen? Naturvårdsverket, Stockholm

Birke, Lynda \& Brandt, Keri (2009). Mutual corporeality: Gender and human/horse relationships Women's Studies International Forum 32(3), 189-197.

Bocz György, Ängelkott (2012). Reutilisation of Agricultural Buildings Tourism and Sustainability in the Swedish Periurban Context Faculty of Landscape Planning, Horticulture and Agricultural Sciences Department of Rural Buildings and Animal Husbandry Alnarp 
Bonow, Madeleine \& Hammer, Monica; \& Petersson, Mona (2017). Hästföretagande i storstadens närhet. I: Bonow, Madeleine \& Rytkönen Paulina (red). YMER 2016 Genus och företagande. Svenska sällskapet för antropologi och geografi.

Boucquey, Noëlle, Campbell, Lisa, Cumming, Gabriel, Meletis, Zoe, Norwood, Carla \& Stoll, Joshua (2012). Interpreting amenities, envisioning the future: common ground and conflict in North Carolina's rural coastal communities. GeoJournal 77(1), 83-101.

Cadieux, Kirsten Valentine \& Hurley, Patrick, T (2011). Amenity migration, exurbia, and emerging rural landscapes: global natural amenity as place and as process. GeoJournal 76(4), 297-30.

Cherry, Todd L \& Rickman, Dan (2010). Environmental Amenities and Regional Economic Development. New York: Routledge

Ching, Barbara \& Creed, Gerald, W (1997). Recognizing Rusticity - Identity and the Power of Place. I: Ching, Barbara. \& Creed, Gerald. W. (red). Knowing your place: rural identity and cultural hierarchy. Routledge: New York.

Eklund, Erland., Andersson, Kjell., Brandt, Nora., Sjöblom, Stefan \& Riska, Elianne (2006). Den nya hästhushållningen, brukargrupper och markanvändning - en utmaning för deltagande planering. Svenska Social- och kommunalhögskolan vid Helsingfors universitet. Forskningsinstitutet, Notat 1/2006, Helsingfors

Elgåker, Hanna (2011) Horse Keeping in Peri-Urban Areas Changing Land Use with Possibilities and Conflicts. Alnarp: Acta Universitatis agriculturae Sueciae (diss.).

Elgåker, Hanna \& Pinzke, Stefan \& Nilsson Christer \& Lindholm, Gunilla (2012). Horse riding posing challenges to the Swedish Right of Public Access. Land Use Policy. 29(2), 274-293.

Forsberg, Gunnel. \& Carlbrand, Elinor (1993). Mälarbygden - en kreativ region? En studie av Mälardalens landsbygd $i$ förändring. Forskningsrapporter från Kulturgeografiska institutionen, Uppsala universitet, nr 107.

Forsberg, Gunnel \& Stenbacka, Susanne (2013). Mapping Gendered Ruralities, European Countryside, 5(1), 1-20.

Ghose, Rina (2004). Big sky or big sprawl? Rural gentrification and the changing cultural landscape of Missoula, Montana. Urban Geography 25(6), 528-549.

Glesbygdsverket (2008). Landsbygdsdefinitioner i Sverige och andra länder. Östersund: Glesbygdsverket.

Gosnell, Hannah, \& Abrams, Jesse (2009). Amenity migration: diverse conceptualizations of drivers, socioeconomic dimensions, and emerging challenges. GeoJournal 76(4), 303-322.

Hammer, Monica., Bonow, Madeleine \& Petersson, Mona (2017). The role of horse keeping in transforming peri-urban landscapes: A case study from metropolitan Stockholm, Sweden. Norwegian Journal of Geography. 71(3), 146-158

Hammer, Monica., Bonow, Madeleine \& Petersson, Mona (2020). Perspectives on horse keeping and welfare in peri-urban landscapes. I: (red). Bornemark, Jonna., Andersson, Petra. \& Ekström von Essen, Ulla. Equine Cultures in Transition. Ethical Questions. London and New York: Routledge.

Heldt, Tobias; Macuchova, Zuzana; Alnyme, Omar \& Andersson, Hans (2018). Samhällsekonomiska effekter av hästnäringen Skattningar baserat på en B.I. - modell av hästnäringen för 2016 Working papers in transport, tourism, information technology and microdata analysis 2018:04
Hjort, Susanne \& Malmberg, Gunnar (2006). The Attraction of the Rural: Characteristics of Rural Migrants in Sweden. Scottish Geographical Journal 122(1), 55-75.

Jordbruksverket (2016). Antal hästar och anläggningar med häst 2004, 2010 och 2016 https://statistik.sjv.se JO0103G8. (Hämtad 8 augusti 2021).

Krannich, Richard \& Luloff, A. E \& Field, Donald R. (2011). People, Places, and Landscapes: Social Change in High Amenity Rural Areas. Springer, Dordrecht, Netherlands:

Laitos, Jan, G \& Ruckriegl Heidi (2013). The Problem of Amenity Migrants in North America and Europe The Urban Lawyer 45(4), 849-914.

Lamont, Michèle \& Molnárm Virág (2002). The Study of Boundaries Across the Social Sciences. Annual Review of Sociology 28, 167-95.

Latimer, Joanna \& Birke, Lydia (2009). Natural Relations: Horses, Knowledge, Technology, The Sociological Review 57 (1), 1-27.

Långstedt, Ulrika. (2008). Förändringar i en traditionsbunden miljö? Om den nya hästnäringen och konsumtionslandsbygden i ljuset av "parabler" och "skript" bland jordbrukare och markägare FISS SSKH Notat 1/2008 svenska social- och kommunalhögskolan vid Helsingfors universitet

Marcouiller, David W., Deller, Steven C. \& Green, Gary Paul (2005). Amenities and Rural Development: Policy Implications and Directions for the Future. I: Amenities and Rural Development: Theory, Methods, and Public Policy, (red) Green, Gary Paul., Steven. C. Deller \& Marcouiller, David. W. Northampton, MA: Elgar.

Matarrita-Cascante, David., Stedman, Richard \& A. E. Luloff (2010). Permanent and Seasonal Residents Community Attachment in Natural Amenity-Rich Areas: Exploring the Contribution of Landscape-Related Factors. Environment and Behavior 42 (2), 197-220.

Qin, Hua (2015). Comparing Newer and Long-Time Residents' Perceptions and Actions in Response to Forest Insect Disturbance on Alaska's Kenai Peninsula: A Longitudinal Perspective." Journal of Rural Studies 39 (c), 51-62.

Robbins, Paul \& Meehan, Katharine \& Gossnell, Hanna \& Gilbertz Susan, J (2009). "Writing the New West: A Critical Review." Rural Sociology 74(3), 356-382.

Rönnblom, Malin (2014). Ett urbant tolkningsföreträde? En studie av hur landsbygd skapas $i$ nationell policy, Umeå, Umeå centrum för genusstudier.

Saltzman, Katharina (2009). Mellanrummens möjligheter. Studier av föränderliga landskap. Stockholm och Göteborg: Makadam Förlag.

Smith, Michael, D \& Krannich Richard, S (2000). 'Culture Clash' Revisited: Newcomer and Longer-Term Residents' Attitudes toward Land Use, Development, and Environmental Issues in Rural Communities in the Rocky Mountain West.” Rural Sociology 65(3), 396-421.

Stenbacka, Susanne (2001). Landsbygdsboende i inflyttarnas perspektiv. Intention och handling $i$ lokalsamhället. Department of Human Geography, Uppsala University.

Stenbacka, Susanne (2011). Othering the rural: About the construction of rural masculinities and the unspoken urban hegemonic ideal in Swedish media. Journal of Rural Studies, 27 (3), 235-244

Stenbacka, Susanne. (2014). Män utanför städerna - om konstruktionen av rurala maskuliniteter och identiteter under förändring SOU 2014:6 bilaga 12.

Sutherland Lee-Ann (2021). Horsification: Embodied gentrification in rural landscapes Geoforum 126: 37-47. 
Tillberg Mattson, Karin (2004). Hästar lockar kvinnor till landsbygden - en studie av hästägare och hästgårdar $i$ Leksands kommun. Arbetsrapport/Working Paper No. 45: Uppsala Uppsala universitet.

Ulrich-Schad, Jessica, D \& Qin, Hua (2018). Culture Clash? Predictors of Views on Amenity-Led Development and Community Involvement in Rural Recreation Counties Rural Sociology 83(1), 81-108.
Winkler, Richelle., Steven Deller, \& Marcouiller Dave (2015). Recreational Housing and Community Development: A Triple Bottom Line Approach. Growth and Change 46(3), 481-500.

Yung, Lourie \& Belsky, Jill. M (2007). Private property rights and community goods: Negotiating landowner cooperation amid changing ownership on the rocky mountain front. Society \& Natural Resources, 20(8), 689-703.

Citera den här artikeln: Madeleine Bonow. 2021. Hästen i det peri-urbana landskapet - vems tolkningsföreträde råder? Kulturella Perspektiv, vol. 30. Tema: Urban norm, s. 1-11

Mottagen: 24 september 2021 Accepterad: 22 december 2021 Publicerad: 04 februari 2022

Copyright: @ 2021 Författaren/författarna. Detta är en Open Access-artikel som distribueras enligt Creative Commons, licens CC-BY 4.0, som tillåter obegränsad användning, distribution och reproduktion i samtliga medieformat, förutsatt att ursprunglig(a) författare och källa uppges. Se http://creativecommons.org/licenses/by/4.0/. 